\title{
Blood Bank
}

National Cancer Institute

\section{Source}

National Cancer Institute. Blood Bank. NCI Thesaurus. Code C51963.

An establishment that collects, tests, processes, and stores blood and its components intended for transfusion or for further manufacture into products used for biological therapies. 